\title{
ARCE ROMERAL, LORENA; SEGHIRI, MIRIAM. LA TRADUCCIÓN DE CONTRATOS DE COMPRAVENTA INMOBILIARIA: UN ESTUDIO BASADO EN CORPUS APLICADO A ESPAÑA E IRLANDA. ÁMSTERDAM: PETER LANG, 2021, 236 PP., ISBN: 978-3-631-80131-4
}

El presente trabajo debería llamar la atención del traductor especializado en lingüística de corpus desde un primer momento por los dos sólidos pilares que respaldan su calidad. En primer lugar, la amplia experiencia de las autoras en el campo de la traducción e interpretación jurídico-económica basada en corpus, reflejada en un extenso ramillete de publicaciones previas sobre traducción de seguros turísticos, contratos de compraventa en diversos idiomas o representatividad de corpus jurídicos, entre otros. En segundo, la obtención del II Premio George Campbell del Aula María Zambrano de Estudios Transatlánticos de la Universidad de Málaga (2019), concedido a trabajos de investigación que innovan con éxito en el terreno de las relaciones España-Irlanda. En la entrega del galardón se subrayó la creatividad de esta obra, calificada como «un contenido original y de gran utilidad para la población residente irlandesa en España».

Tras un breve prefacio, en la introducción de la obra se esboza la estructura del libro, organizado en torno a tres capítulos y unas conclusiones finales. En el primer capítulo, las autoras se proponen delimitar el objeto de estudio: el contrato de compraventa de viviendas en español (en la variedad peninsular) e inglés (variedad irlandesa). Para ello, enmarcan la traducción de este tipo de textos en el ámbito de la traducción jurídica y este a su vez en la traducción especializada. La demanda de redacción y traducción de los contratos de compraventa de viviendas en España e Irlanda queda sobradamente justificada mediante numerosos argumentos amparados en datos oficiales y estadísticas elaboradas por prestigiosas entidades independientes. El aumento de los intercambios turísticos y migratorios, motivado por la mejora de las conexiones y el acelerado crecimiento económico de la isla esmeralda a partir de la década de los noventa, ha provocado que España se haya convertido en el primer destino vacacional de los irlandeses. Más concretamente, el litoral mediterráneo se perfila como el lugar preferido por los turistas para establecer segundas residencias, gracias a «la excelente climatología, la buena relación calidad-precio, el entorno natural y medioambiental y el alto nivel de infraestructuras y comunidades existentes» (p. 24). Cada vez más turistas irlandeses responden al perfil de "parejas de mediana edad, de poder adquisitivo medio-alto, mayoritariamente profesionales liberales o empleados cualificados de empresas medianas y grandes, que se plantean la compra de bienes inmuebles como segunda residencia con el propósito de convertirla en 
vivienda habitual al jubilarse» (p. 25). A su vez, Irlanda se ha convertido en el mercado inmobiliario con mayor auge de la Unión Europea, con una demanda de viviendas superior al ritmo de construcción.

El segundo capítulo, de corte teórico-metodológico, tiene como objetivo la compilación de un corpus bilingüe (inglés-español) de contratación inmobiliaria orientado a la compraventa de viviendas, de acuerdo con un protocolo sistematizado que asegure su representatividad tanto desde el punto de vista cualitativo como cuantitativo. Así, las autoras se acercan al concepto de corpus, entendido como una colección de textos que debe ser representativa y atender a criterios explícitos y propósitos específicos. Para los traductores e intérpretes, estas colecciones constituyen una fuente documental capaz de proporcionar modelos y patrones que los guían en sus procesos de toma de decisiones a nivel macro y microestructural. Además, dada la importancia de la legislación aplicable en el ámbito de la traducción jurídica, se proyecta una división en dos subcorpus. De una parte, una colección que contiene la normativa sobre compraventa inmobiliaria aplicable en los ordenamientos jurídicos de España e Irlanda (LEGISCOR). De otra, un subcorpus exclusivo de contratos de compraventa de viviendas en español peninsular e inglés de Irlanda (INMOCOR). La representatividad cualitativa de ambos subcorpus queda asegurada gracias al establecimiento de unos parámetros de diseño claros y de un protocolo de compilación en cuatro fases (localización de textos, descarga, formato y almacenamiento). La representatividad cuantitativa, por su parte, es comprobada mediante ReCor, software merecedor del premio en Tecnología de la Traducción de España (2007) en cuyo diseño ha participado una de las coautoras (Miriam Seghiri). Este programa informático es capaz de determinar la representatividad de los corpus en función de su tamaño a través del algoritmo N-Cor. Como broche de este capítulo, se describen los llamados «programas de gestión de corpus» multilingües y comparables, que permiten interrogar compilaciones de textos de manera automática o semiautomática ( $p$ 51). En este caso, las herramientas elegidas han sido WordSmith Tools y AntConc.

El tercer capítulo recoge la explotación del corpus compilado como herramienta para la traducción directa e inversa, la extracción terminológica y fraseológica y el estudio de la macro y microestructura de los contratos de compraventa de viviendas. En primer lugar, se emplea el programa WordSmith Tools para la extracción terminológica y conceptual de LEGISCOR (apartado 3.2.). Mediante diversas técnicas, las autoras extraen equivalentes de conceptos jurídicos relativos a la compraventa de viviendas en ambos ordenamientos (español e irlandés) y proponen traducciones directas e inversas adaptadas a dichas realidades jurídicas. En el apartado 3.3., se describe la utilización de AntConc para la elaboración de un glosario 
bilingüe y bidireccional (inglés-español/español-inglés) basado en el corpus INMOCOR. Haciendo gala de una gran intuición didáctica, las autoras incluyen también en este recurso la transcripción fonética de los términos en ambos idiomas. Como colofón, los resultados obtenidos en los dos apartados mencionados sirven de base a una de las producciones más interesantes del estudio, las plantillas de redacción de contratos (apartado 3.4.). De nuevo se emplean AntConc e INMOCOR con objeto de crear plantillas que semiautomaticen el proceso de redacción de los contratos de compraventa de viviendas en español de España e inglés de Irlanda. Como aclaran las autoras, una plantilla de este tipo proporciona una valiosa guía al usuario de un género textual flexible en ambas variedades diatópicas, pues «hay datos personales de las partes que siempre tendrán que ser incluidos manualmente» y «existen cláusulas que pueden ser potestad de las partes que estén o no en el contrato, o que, siendo obligatoria su inclusión, esta pueda contar con distintas formas y contenido» (p. 90). Estas divergencias en la macroestructura textual se analizan mediante la búsqueda por concordancias de AntConc y se contrastan en una ilustrativa tabla ubicada en el apartado 3.4.1.3. Por último, las convenciones analizadas se emplean para implementar sendas plantillas de redacción en español e inglés. En el caso del español, la plantilla se encuentra disponible en formato Excel (.xls) en dos direcciones web distintas, permitiendo una de ellas cumplimentar los campos del contrato, así como la elección de las partes que lo componen para su posterior descarga (apartado 3.4.2.). La plantilla irlandesa, por su parte, tiene un carácter más constreñido, ya que cuenta con una forma ad solemnitaten prescrita por la Law Society of Ireland. Para facilitar la redacción por parte del usuario, este modelo se ofrece hasta en tres formatos distintos (Word, PDF y Excel). La gratuidad, accesibilidad y el carácter auxiliar que las plantillas pueden tener para un diverso número de profesionales (p. ej. lingüistas, traductores e intérpretes, juristas o agentes inmobiliarios), unidos a un gran valor práctico, son los principales motivos que hacen de este recurso uno de los más aprovechables de esta investigación. No cabe duda de que la transferencia de estos resultados puede suponer un gran impacto no solo a nivel investigador, sino también para el tejido empresarial.

En suma, las autoras nos ofrecen una obra de carácter extremadamente funcional, concisa, de fácil lectura y abundante en gráficos y ejemplos. Esta claridad también se deja ver en la estructura, especialmente en un índice que compartimenta a la perfección cada uno de los estudios acometidos (por lengua, por herramienta de gestión de corpus empleada, etc.). La persecución de unos objetivos de investigación bien fijados desde el principio culmina en la creación de varias herramientas lingüísticas que destacan por su carácter transversal, lo que refuerza el potencial interdisciplinar y social de los estudios de traducción basados en corpus. 
Como se señala en las conclusiones, la utilización efectiva de estos recursos supondrá un impacto positivo en el sector económico de la compraventa de viviendas entre España e Irlanda, al ahorrar tiempo y posibilitar incluso la supresión de intermediarios en el proceso. En este sentido, el libro reseñado cobra una especial importancia al enmarcarse en el contexto del turismo en España, un sector en el que tras una crisis tan honda como la del coronavirus toda ayuda a la reactivación de los engranajes económicos es bien recibida.

[FERNANDO SÁNCHEZ RODAS] 